\title{
Negociando a avaliação do estágio docente: uma análise a partir do Sistema de Avaliatividade
}

\author{
Carla Cristina de Souza
}

Pontifícia Universidade Católica do Rio de Janeiro - PUC-Rio / IFRJ

\begin{abstract}
Resumo
Este trabalho tem como objetivo analisar como as professoras da universidade e da escola de estágio constroem a avaliação do estágio durante as discussões sobre a prova de aula de uma licencianda para a atribuição do grau final da disciplina. Este é um contexto pouco explorado em Linguística Aplicada, área na qual este estudo se insere. Partes dessa interação foram examinadas com base no arcabouço teórico do Sistema de Avaliatividade, observando a ocorrência e tentando interpretar o porquê do uso de instanciações de atitude, engajamento e gradação. Os resultados indicam a utilização de recursos avaliativos não só para avaliar a aula ou o estágio em si, mas também a aluna e suas ações. Além disso, é possível perceber uma grande desigualdade de poder velada entre os participantes na negociação da intersubjetividade que, como premissa, deveria ser evitada.

Palavras-chave: Linguística Aplicada, Estágio Supervisionado, Sistema de Avaliatividade.
\end{abstract}

\begin{abstract}
The objective of this article is to analyze how the university school teachers build together the evaluation of a languages student's internship after a class exam to decide on the grade in the subject. This context is in Applied Linguistics, an area which this research is aligned with. Parts of this interaction were examined based on the theoretical framework of the Appraisal System, by observing the occurrence of attitude, engagement and gradation and trying to understand the reasons for their usage. The results indicate that not only are the class and the internship itself evaluated, but also the student and her behavior. Moreover, while the participant teachers are negotiating the intersubjectivity, there can be perceived a major covert imbalance in power between them, which, as a premise, should be avoided.

Keywords: Applied Linguistics, Supervised teacher-training internship, Appraisal System.
\end{abstract}

\section{INTRODUÇÃO}

Inserido na área de Linguística Aplicada (Miller, 2013), este trabalho está voltado para o contexto pedagógico, mais especificamente para o estágio supervisionado na formação de professores. Apesar de muitas vezes ser considerado apenas como um período em que o licenciado pode observar a teoria posta em prática (Celani, 2001, p. 
34), o estágio pode ser uma oportunidade para problematização, pesquisa e reflexão, não só para os estagiários (Pimenta e Lima, 2004), mas também para os outros professores envolvidos. Essa visão é corroborada por Miller (2013, p. 116), que aponta para uma necessidade urgente de envolver os diferentes professores do estágio em reflexões investigativas sobre a etapa de pré-serviço. Motivada a me engajar nessa empreitada, por ser integrante dessa prática social como professora regente, proponhome, neste trabalho, a examinar o momento de avaliação do estágio, ponto pouco explorado em pesquisas na área de Linguística Aplicada.

O presente estudo consiste na busca de entendimentos sobre a forma como ocorre a negociação da avaliação final de uma licencianda de Letras após sua prova de aula no estágio de inglês para fins específicos, desenvolvido em uma escola de ensino médio e técnico do Rio de Janeiro. Portanto, o objetivo desta pesquisa é analisar como as professoras da Prática de Ensino e regente se posicionam e constroem a avaliação e a intersubjetividade discursivamente no processo decisório da nota de estágio.

Para tanto, analiso uma interação transcrita do áudio da conversa entre as professoras formadoras com base no arcabouço teórico da Linguística SistêmicoFuncional $^{1}$ (Halliday e Matthiessen, 2004), que entende a linguagem como um potencial para construir sentidos, ou seja, um conjunto de alternativas orientado para o uso. Dentro desta perspectiva, esta pesquisa se orienta mais especificamente a partir do Sistema de Avaliatividade (Martin e White, 2005, Vian Jr, 2009), pois tenho como foco o estudo dos significados interpessoais nos trechos examinados e essa abordagem investiga como usuários da língua se posicionam em seu discurso e oferece formas de analisar quais os recursos avaliativos o falante/escritor utiliza para negociar sentidos nas interações.

Na próxima seção, passo então à descrição dos pressupostos teóricos, destacando principalmente os diferentes recursos interpessoais para negociação com base no Sistema de Avaliatividade, para logo depois passar à análise de três excertos da conversa entre as professoras. Finalmente, sintetizo os principais aspectos discutidos e apresento algumas possíveis conclusões sobre as interpretações feitas, nas considerações finais.

1 Para mais detalhes sobre a Linguística Sistêmico Funcional, ver: Halliday e Hasan, 1991; Thompson 1996; Ravelli, 2000; Eggins, 2004; Ghio e Fernandez, 2008; Gouveia, 2009; e Halliday e Matthiessen, 2014. 


\section{O SISTEMA DE AVALIATIVIDADE E AS CATEGORIAS DE ANÁLISE}

$\mathrm{Na}$ interação, estamos constantemente fazendo escolhas entre os diversos recursos que a língua nos oferece para avaliar o que incluímos em nossos textos, sinalizando para o leitor/ouvinte nossas atitudes quanto ao que expressamos. Partindo da perspectiva sistêmico-funcional da linguagem (Halliday e Matthiessen, 2004), o Sistema de Avaliatividade leva a análise para além da oração (Martin e White, 2005, p. 12 e 33) e dá conta dos significados interpessoais no nível da semântica do discurso. Através deste sistema foi possível examinar a avaliação e a perspectiva pela categorização de suas ocorrências na transcrição.

O Sistema de Avaliatividade é dividido em três subsistemas presentes simultaneamente no texto: atitude, gradação e engajamento. O subsistema de atitude compreende os recursos semântico-discursivos associados à emoção e pode ser categorizada em três tipos: afeto, julgamento e apreciação. A gradação engloba as estratégias para amplificar ou atenuar as emoções e indicar a fonte de nossa avaliação e se subdivide em força e foco. Já o engajamento abarca os mecanismos para "orquestrar vozes no texto" (Vian Jr., 2012, p.121) e por meio dele pode-se identificar o quanto as professoras se comprometem em relação ao que falam e as estratégias que usam para tentar convencer uma à outra. O engajamento pode ser de expansão dialógica ou contração dialógica. Veremos abaixo cada um desses subsistemas e suas categorias separadamente.

\section{Atitude}

A análise da atitude é apropriada para mostrar como as professoras expressam sua opinião através de respostas emocionais, que podem ser demonstradas explicitamente (inscritas) ou estar subentendidas (evocadas). Além disso, é possível reconhecer se o tópico avaliado (objeto, situação, fato, evento ou pessoa) é mostrado de forma positiva ou negativa.

O afeto, que trata dos recursos usados na construção dos sentimentos, é a categoria central da atitude, sendo recontextualizado como julgamento (quando expressamos o que sentimos quanto ao comportamento de outros) e apreciação (quando expressamos o que sentimos quanto a coisas) (Martin, 2000, p.147). Contudo, no afeto, o posicionamento está voltado para o próprio avaliador, enquanto que no julgamento e na apreciação, o foco recai sobre o que está sendo avaliado. $O$ afeto pode ser 
classificado em três categorias: felicidade/infelicidade, segurança/insegurança e satisfação/insatisfação.

O julgamento trata das avaliações morais do comportamento humano. Aprovamos ou condenamos o que as pessoas fazem a partir das expectativas que temos sobre como agir em nossa cultura e essas avaliações podem estar orientadas de acordo com sanções sociais ou lidar com a estima social. Os julgamentos de sanção social são emitidos com base no que é legal ou moralmente tomado como digno de louvor ou punição. Esse grupo se subdivide em veracidade (o quão sincero ou confiável alguém é) e propriedade (o quão correto a pessoa é). Entretanto, quando o que está em jogo é a conduta pessoal e psicológica do indivíduo, que é culturalmente admirada ou criticada, estamos lidando com o grupo de significados classificados como estima social, que se subdivide em normalidade (o quão normal alguém é), tenacidade (o quão decidido alguém é) e capacidade (o quão capaz alguém é).

A apreciação é o campo dos significados usados para construir avaliações dos produtos feitos pelo homem, fenômenos naturais e estados de coisas. Os casos em que as qualidades estéticas de pessoas são examinadas serão também classificados como apreciação por serem avaliadas como objetos (em contraste com os exemplos em que analisa-se o comportamento dessas pessoas, o que seria julgamento). A apreciação pode ser de três tipos: reação (se o que está em questão atrai nossa atenção e que tipo de impacto tem), composição (diz respeito ao como percebemos o grau de complexidade e proporcionalidade do item avaliado), e valor (qual a significância social desse item).

\section{Engajamento}

Segundo Martin e White (2005, p.92-93), o engajamento abarca as estratégias que o autor/falante usa para negociar seus argumentos, comprometendo-se ou não com o que é dito ou escrito. Para tanto, ele pode orientar seu texto de forma a promover a expansão dialógica (levantando posições e vozes dialógicas alternativas) ou a contração dialógica (agindo no sentido de limitar, dispersar ou se opor a outras posições ou vozes). Assim, através da análise desses recursos pode-se perceber como as professoras se posicionam em relação a seu próprio enunciado e aos enunciados da sua colega.

Segundo Vian Jr. (2011, p.36), recursos para expansão dialógica se subdividem em entretenimento e atribuição. $\mathrm{O}$ entretenimento inclui as formas não autoritárias para indicar o posicionamento da voz autoral fazendo com que seu argumento seja visto como uma das alternativas possíveis, não descartando outras possibilidades. Isso pode ser feito pelo uso, por exemplo, de auxiliares modais (poder, dever), adjetivos (possível, 
provável), expressões (as evidências sugerem que) e processos (suspeitar, duvidar, parecer). Já a atribuição compõe-se dos recursos em que se confere a uma ou mais vozes externas a responsabilidade por certa opinião. A atribuição subdivide-se em reconhecimento (quando a voz autoral não avalia a argumentação da fonte externa, apenas a cita) e distanciamento (quando a voz autoral se exime da responsabilidade pela proposição externa, deixando claro que não rejeita sua ligação com tal posicionamento).

Por outro lado, os recursos de contração dialógica podem ser de discordância ou proclamação (White, 2004). A discordância pode usar a negação ou a contraargumentação para refutar, recusar, atacar ou transformar certo ponto de vista trazido para o texto. A proclamação, por sua vez, subdivide-se em concordância (mostram alinhamento total entre interlocutores), pronunciamento (a voz autoral rejeita as possíveis opiniões alternativa declarando sua resistência a elas) e endosso (recursos que asseveram a opinião alternativa, tomando-a como legítima e/ou inegável). Assim, o sistema de engajamento foi usado na análise para investigar como, além de defender um posicionamento, as participantes convidam uma a outra a compartilhar de suas avaliações.

\section{Gradação}

A gradação engloba os recursos que o falante/escritor usa para ajustar (realçar ou suavizar) suas avaliações e permeia os sistemas de atitude e engajamento, modificando a natureza dos significados dentro de suas escalas. Desse modo, o falante/autor pode construir diferentes graus de positividade ou negatividade para ressaltar ou ofuscar avaliações de afeto, julgamento e apreciação, bem como elevar ou diminuir a intensidade utilizada ou seu investimento na defesa de seu argumento (Martin e White, 2005, p. 136).

A categoria foco se refere à precisão de uma avaliação e se restringe aos recursos que, apesar de não fazerem parte de uma escala gradativa, agem naquele contexto como graduadores do item avaliado (Vian Jr., 2009, p. 118). A categoria força, por sua vez, modifica a avaliação em termos de quantidade e intensidade.

\section{INVESTIGANDO A AVALIAÇÃo DA PROVA DE AULA: METODOLOGIA}

Essa pesquisa, de caráter qualitativo e interpretativo (Denzin e Lincoln, 2006), foi desenvolvida a partir de dados gerados em uma reunião de duas professoras para a avaliação do estágio de uma licencianda logo após sua prova de aula em inglês. A 
conversa foi gravada em áudio e transcrita com base em critérios da Análise da Conversa (Sacks, Schegloff e Jefferson, 1974; Garcez, Bulla e Loder 2014). Por questões éticas, os nomes das participantes e das instituições, bem como quaisquer informações que possam identificá-las, foram alterados.

A investigação foi realizada em uma escola de ensino médio-técnico do Rio de Janeiro, onde a licencianda de Letras, com dupla habilitação (Português e Inglês), cumpriu 240 horas de estágio. A conversa transcrita ocorreu como parte do processo de avaliação final da disciplina de Prática de Ensino e conta somente com a participação da professora regente (Ana), responsável pelo acompanhamento da licencianda (Lívia) na escola de estágio, e pela professora da universidade (Marta), que vem à escola somente para observar e avaliar as aulas ministradas pelos estagiários. Convém destacar que, apesar de se encontrarem somente nessas ocasiões, as professoras desenvolveram uma relação de amizade e parceria, que tem influência na forma que expõem seus argumentos.

A análise se atém apenas ao momento após a prova de aula de Lívia, em que as professoras discutem suas avaliações sobre o estágio da licencianda, principalmente sobre a aula que ela apresentou. Antes da aula, cada professora recebe uma cópia do plano de aula e a ficha de avaliação, documentos usados por elas para fazer anotações durante todo o processo. Terminada a aula, a turma é dispensada e os estagiários também saem, ficando apenas as professoras regente e de Prática de Ensino para discutir e tomar a decisão sobre a nota do estágio. Tal discussão foi feita seguindo alguns passos, nesta ordem: 1) professora regente faz avaliação geral da aula em um turno longo, enquanto a outra só ouve; 2) discussão conjunta sobre o estágio e a estagiária como um todo e dos pontos fracos e fortes da aula; 3) fechamento das notas para cada bloco de critérios da ficha de avaliação e 4) decisão da pontuação final da estagiária a partir da média das notas dadas pelas duas professoras. É importante ressaltar que fica combinado previamente que as duas professoras têm o mesmo poder de decisão quanto à avaliação de licenciandos, informação dada aos estagiários no processo de preparação da aula, quando eles têm acesso à ficha que será utilizada no dia da prova de aula pelos professores formadores, e repetida no dia da apresentação da mesma, quando todos os participantes se encontram.

Da conversa em questão, foram retirados três trechos que correspondem a um ponto da ficha de avaliação: o início da interação (as primeiras falas e o primeiro tópico da aula a ser discutido), o meio (marcado por meio dos minutos de duração) e o fim da 
interação (com o fechamento da nota). Para melhor localização de alguns pontos que serão discutidos, uso negrito para destacá-los nas transcrições. Na próxima seção passo, então, às análises e suas possíveis interpretações.

\section{A AVALIAÇÃO DO ESTÁGIO EM NEGOCIAÇÃO: A ANÁLISE DOS DADOS}

A análise aqui apresentada começa depois da prova de aula de Lívia, quando as professoras Ana e Marta estão sozinhas na sala, reunidas para decidir a nota de estágio. Ana (a professora regente) parece preocupada, quando Marta pergunta "o que você achou da aula dela?". Em todas as provas de aula, Marta pede que o professor regente faça uma avaliação geral do estágio primeiro, para só depois começar a tecer comentários, o que também acontece na interação aqui transcrita, como pode ser visto no trecho 1 .

\section{$\underline{\text { Trecho } 1}$}

\begin{tabular}{|l|l|l|}
\hline Marta & 1 & e aí? (.) o que você achou da aula dela? \\
Ana & 2 & olha Martinha (.) \\
& 3 & tô um pouquinho assim \\
& 4 & meu coração>tá um pouquinho assim< <(em tom de aflição, põe as mãos no coração)) \\
& 5 & porque é (.) eu eu gostei muito quando ela me mostrou o planejamento, \\
& 6 & ela me ligou...a gente... fiz comentários. não deu tempo de você ver também \\
& 7 & ela falou que foi nesse final de semana que ela terminou \\
& 8 & e por conta da mudança mesmo da turma né? \\
& 9 & que ia ser em uma e depois teve que passar para outra \\
& 10 & por conta do trabalho que ela vai sair com mais pressa (.) então assim \\
& 11 & eu eu gostei muito da da ideia do planejamento \\
& 12 & (.) achei bem amarrado e logicamente articulado \\
Marta & 13 & a realização é que não foi... não ficou... \\
Ana & 14 & \\
& 15 & [a implementação] \\
& 16 & eu só senti a diferença entre o que ela planejou ((coloca as mãos no coração)) \\
& 17 & que a concepção foi muito boa \\
& 18 & pessoalmente pelo tempo que ela teve (.) porque ela mudou de turma e de tema \\
& 19 & embora ela ia usar complain também \\
& 20 & e ela conseguiu pensar numa aula super... interessante \\
& 21 & com foco no texto argumentativo \\
& 22 & eu achei que foi ela formou as perguntas de forma encadeada \\
& 23 & e realmente que que cumpriu o objetivo que era elicitar né? os recursos do texto \\
& 24 & argumentativo \\
& 25 & a função do discurso direto ((lendo as anotações)) \\
& 26 & isso foi super... né? bem marcado \\
& 27 & então achei a concepção da aula muito boa \\
\hline
\end{tabular}




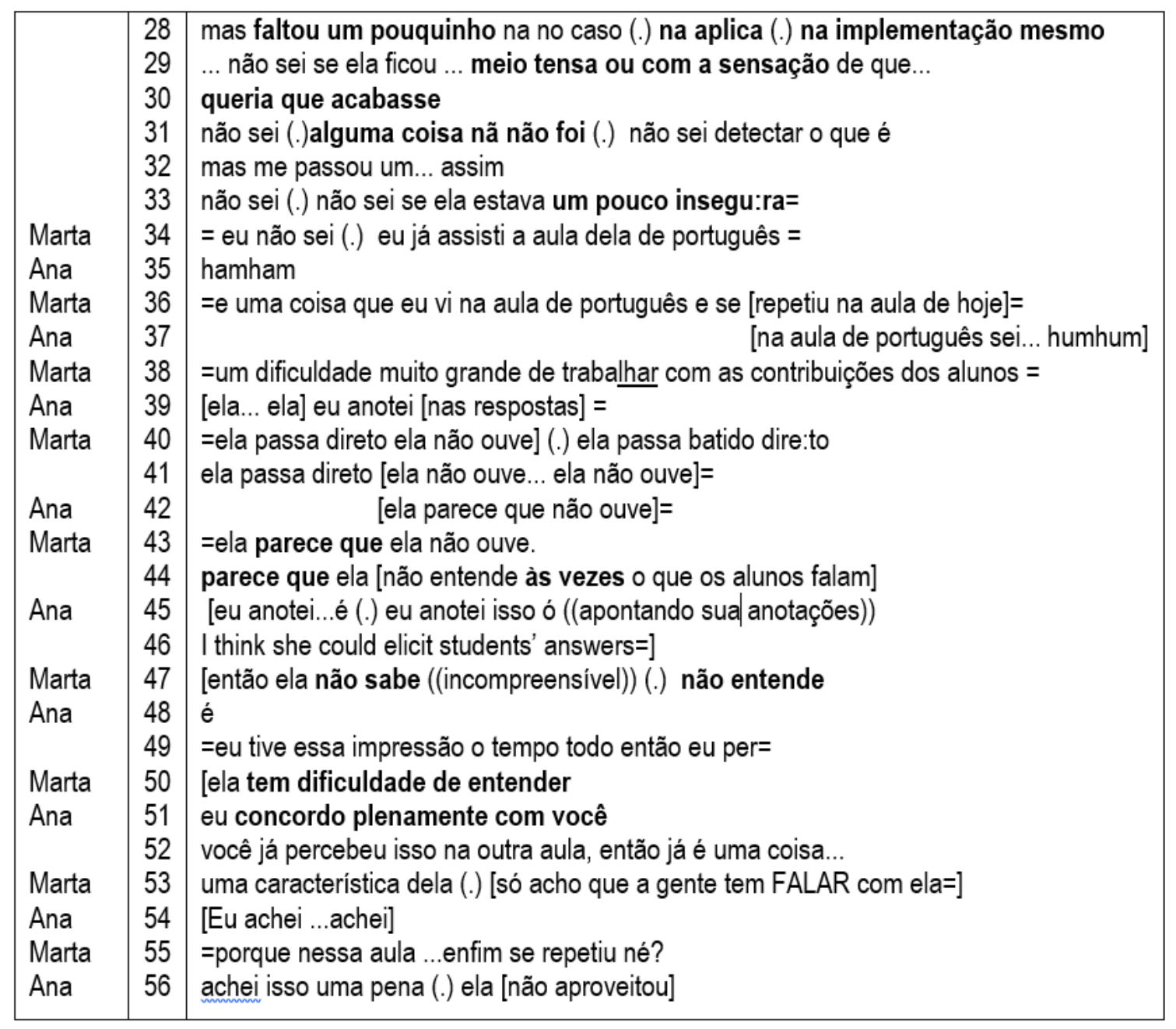

Ana toma um turno longo para responder à pergunta, pautando seus argumentos principalmente em impressões permeadas de emoções, por atitude, seguidas de várias explicações, que procuram conferir legitimidade ao seu argumento (Micheli, 2010). Assim, ao invés de falar simplesmente "a aula foi boa, mas teve alguns problemas", ela já inicia seu discurso de forma que ele fique carregado de afeto ao mencionar seu coração (linhas 3 e 4), o que, somado às suas expressões e voz, demonstra sua ligação emocional com a avaliação e introduz a ideia de que há algo errado, mas ela não se sente bem em criticar. Outras escolhas lexicais permeadas de afeto chamam a atenção nessa introdução e organizam seus argumentos, o que ganha maior ênfase pelos gestos e pelas mudanças no tom de voz de Ana. Assim, ela volta as mãos para o coração em sinal de angústia e na linguagem verbal também se destaca o afeto para explicar o porquê do incômodo: ela diz que gostou muito do planejamento (na linha 5, o que é reforçado ao repetir na linha 11), mas que "só sentiu diferença entre o que ela planejou" 
e o que realmente foi feito, frase que ela não consegue completar talvez para evitar mencionar aspectos negativos.

Parece que, na busca por se ater aos pontos positivos, ela começa a listar tais pontos por apreciação (como em "achei bem amarrado, logicamente articulado" na linha 12 e em "a concepção foi muito boa", na linha 16, o que é repetido na linha 26) como também avaliando a licencianda por julgamento positivo sobre sua capacidade em "ela conseguiu pensar numa aula super... interessante", "ela formou as perguntas de forma encadeada" e "realmente que que cumpriu o objetivo" (linha 22). Note-se que o uso da gradação para ampliar a força e o foco se faz muito presente em tais avaliações. Ela também menciona duas vezes (nas linhas 6 a 10 e na 18) o fato de a licencianda ter enfrentado problemas para fazer a aula no dia previamente combinado e ter que mudar tudo, tanto para justificar as suas falhas como para talvez transmitir a ideia de que ela fez bem apesar das adversidades e ganhar a simpatia da outra professora avaliadora.

Os aspectos negativos, por outro lado, são minimizados ou camuflados nas falas de Ana. Observamos a gradação nas partes destacadas em " faltou um pouquinho", "ela ficou ... meio tensa" e "não sei se ela estava um pouco insegu:ra"(nas linhas 28 , 29, 30 e 33), que suavizam muito essas declarações. Por outro lado, mesmo não sendo desvelado, podemos perceber, a partir do gesto em direção ao coração e suas palavras nas linhas 3 e 4, que houve algum problema. Entretanto, ele não é mencionado até a linha 13, em que Ana tenta elaborá-lo parecendo ter dificuldade para achar a palavra adequada, mas, logo após a correção da colega, ela usa o comparativo a fim de diminuir a intensidade de sua opinião: "a implementação não foi tão boa quanto eu esperava", o que classifica a implementação como boa, apenas aquém da expectativa, ideia reiterada na sua próxima fala com o vocábulo "só" (linha 16).

Como alegação pelas falhas cometidas, Ana avalia a licencianda atributivamente por meio de afeto - insegurança da linha 28 até a 33. O uso de emoções parece ser um artifício para conseguir a aquiescência e empatia de Marta quanto às opiniões de Ana e construir intersubjetividade. Pelo mesmo motivo, a regente também usa estratégias de expansão dialógica pelo uso recorrente de "achei", por exemplo, que mostra que sua visão não é restritiva.

Logo depois da pequena interferência com fala sobreposta de Marta, usada para fazer um reparo na linha 14, Ana retoma sua avaliação adotando o termo sugerido pela outra professora e até se autocorrige na linha 28, mostrando a intenção de estar em sintonia com a outra avaliadora. No entanto, já na pequena inserção da professora de 
Prática de Ensino usada para corrigir a colega, podemos perceber uma tendência de Marta em direção a se estabelecer como condutora da conversa, criando assimetria.

A argumentação de Marta é construída de forma a avaliar negativamente a aula da estagiária em grande parte da reunião, discordando, portanto, de Ana. A primeira marca que assinala sua divergência de opinião é o "eu não sei” na linha 34 , seguido da apresentação de um conhecimento não compartilhado com Ana: o que aconteceu na prova de aula de português da licencianda Lívia. Essa menção é uma informação nova para a professora regente e a impede de contribuir com seu parecer sobre esse aspecto, o que faz com que ela tenha que aceitar o julgamento da colega.

Marta faz referência à aula de português para construir a ideia de que, ao contrário do que Ana disse, a apresentação teve um problema sério por causa de um comportamento da estagiária, já observado anteriormente somente pela professora da universidade. A professora regente primeiramente mostra-se disposta a seguir a nova orientação da outra participante (com "hamham" e em "na aula de português sei... humhum") e Marta se certifica de que Ana está realmente acompanhando sua linha de pensamento (“entendeu?"). A partir desse momento, encontram o primeiro ponto em comum em suas observações e repetem seguidamente (do turno 10 ao 21 ), reforçando a ideia de que estão agora em sintonia. Mesmo assim, apesar de começar modalizando (usando expressões como parece que e às vezes em "parece que ela [não entende] às vezes o que os alunos falam", repetindo o que Ana fala um pouco antes), Marta é muito mais assertiva ao julgar a aluna negativamente ("então ela não sabe", "não entende" e "ela tem dificuldade mesmo") contraindo cada vez mais o discurso dialogicamente. Por fim, Marta consegue concluir mais claramente seu argumento, dizendo que ignorar os alunos é "uma característica dela" (da estagiária). A professora regente tenta, em 27, falar algo, mas é interrompida pela colega, que recupera mais uma vez o ocorrido na aula de português. Ana então avalia a situação, novamente com base na emoção por afeto e julgamento: "achei isso uma pena (.) ela [não aproveitou]".

No início de trecho 2, vemos que Marta volta a ressaltar sua opinião ao tecer comentários negativos sobre algumas características por afeto, com gradação alta (“muito TÍMIDA" na linha 198, avaliação ainda mais realçada pela subida de tom de voz), e por julgamento das ações de Lívia. Seu posicionamento aparece, muitas vezes, de forma enfática por meio de recursos de contração dialógica como, por exemplo, ao aumentar a voz (linhas 198 e 200) e trazendo elementos para logo depois contrapô-lo (como em " ela até veio pra frente para os alunos fazerem aquela atividade, mas ainda 
estava longe" . O 'até' minimiza a avaliação positiva por julgamento-capacidade sobre o que a licencianda acertou (ela "veio pra frente", linha 202), mas a segunda oração reforça a ideia de que isso não foi o bastante. Novamente, Ana tenta argumentar a favor da estagiária, mas quase não consegue falar pois é interrompida pela colega:

\section{$\underline{\text { Trecho } 2}$}

\begin{tabular}{|l|l|l|}
\hline Marta & 198 & [ela ficou] muito TiMIDA (.) ficou muito tempo ali atrás da mesa \\
Ana & 199 & [humhum] ((tosse)) \\
Marta & 200 & meio que se ESCONDENDO ali no quadro \\
Ana & 201 & humhum \\
Marta & 202 & ela até veio pra frente para os alunos fazerem aquela atividade \\
& 203 & mas [ainda estava longe] \\
Ana & 204 & [isso]... \\
& 205 & ela deu atenção (.) acho que ela foi se soltando um pouquinho mais pro final, né?= \\
Marta & 206 & é (.) mas acho que sempre nessa... ela se soltava >os alunos falavam< \\
& 207 & se soltava e se continha né? \\
Ana & 208 & [humhum] \\
\hline
\end{tabular}

No trecho 2, a interação continua a ser construída cooperativamente, com Marta avaliando e Ana reiterando sua atenção ("humhum", "isso"), parecendo concordar. Na linha 205, entretanto, a professora regente afirma que Lívia deu atenção aos alunos (o que contradiz a ideia desenvolvida por Marta nos turnos anteriores), mas faz uma pequena pausa e então diminui mais uma vez o grau de adesão quanto à sua proposição, modalizando-a para aumentar o engajamento ("acho que ela foi se soltando um pouquinho mais pro final, né?").

Nos momentos finais da conversa, Marta e Ana tentam traduzir a discussão em números, pois tem que dar uma nota para a estagiária. No entanto, elas têm um pouco de dificuldade de chegar ao consenso, como pode-se perceber em dois momentos de longos silêncios marcados no trecho 3 .

\section{Trecho 3}

((as professoras ficam o tempo todo comparando suas fichas de avaliação e às vezes mudam o que escreveram)) 


\begin{tabular}{|l|l|l|}
\hline Marta & 296 & <acho que o vídeo foi pouco aproveita:do> \\
Ana & 397 & > poderia ser melhor aproveitado< (9,3) \\
Marta & 398 & mas enfim acho que eu tiraria um meio dela pela seleção dos conteúdos \\
Ana & 399 & acho que tá legal \\
Marta & 400 & eu também acho $($.$) acho que escolheu bem o texto ($.$) né?$ \\
Ana & 401 & um texto atual (.) um texto interessante \\
& 402 & também pelo tema desperta a sua curiosidade né? \\
Marta & 403 & acho também que essa adequação estava de acordo $(8,2)$ \\
& 404 & cla-reza e objetividade assim, eu não (.) acho até que foi objetivo demais. \\
& 405 & mas claro eu não sei, porque ela fazia o que estava previsto na folhinha \\
Ana & 406 & hamham \\
\hline
\end{tabular}

\begin{tabular}{|l|l|l|}
\hline Marta & 407 & tudo que estava previsto na folhinha os alunos tinham acesso \\
& 408 & e eles são são bons e então conseguiram entender então (.) eu não sei \\
Ana & 409 & acho que ela foi uma aula (.) que ousou pouco \\
& 410 & ousou pouco é é (.) >ficou mais como a gente falou< \\
& 411 & >que você falou< (.) na zona de conforto de segurança \\
Marta & 412 & é: controlar o máximo possível os imprevistos né? que pudessem surgir \\
& 413 & bom assim, na ... >uma avaliação que eu faço< (.) < procedimentos didáticos> \\
& 414 & eu daria algo em torno de vinte e cinco no máximo trinta \\
& 415 & porque aí acho que no má:ximo seria uma aula oito \\
Ana & 416 & [pensando nisso] acho que ela é uma aula sete e meio ou oito mesmo \\
& 417 & [entendi (.) entendi] \\
Marta & 418 & é: eu fiquei também assim (.) é.: lamentando né? \\
Ana & 419 & mas oito é uma nota boa \\
& 420 & é uma nota boa \\
& 421 & mas assim (.) pensando mesmo no: que ela preparou é: \\
& 422 & fiquei um pouco nem foi decepcionada \\
Marta & 423 & mas eu fiquei lamentando mesmo \\
Ana & 424 & puxa uma aula tão rica, tão boa (.) realmente acho que isso \\
Marta & 425 & você acha trinta eu acho uns vinte e cinco, fica vinte e oito = \\
Ana & 426 & isso (.) [ perfeito \\
Marta & 427 & =entendeu? \\
\hline
\end{tabular}

Como podemos notar, Marta sempre inicia a avaliação, lendo e sugerindo os tópicos que devem ser preenchidos na ficha, cabendo a Ana somente concordar e complementar o que é dito. Ana até mesmo retoma as falas da outra professora para confirmar o argumento usado (como em $>$ ficou mais como a gente falou $<$ (.) $>$ que você falou< (.) na zona de conforto de segurança). O "a gente falou" no exemplo citado, mesmo que modificado logo depois em "que você falou", acentua essa ideia de alinhamento entre as duas, de tentativa de comunhão de sentidos.

Marta, por sua vez, usa o "acho" como recurso de expansão dialógica, mas continua veemente nas avaliações negativas (por julgamento negativo da aluna como em "ela fazia o que estava previsto na folhinha" na linha 405, e por apreciação também negativa da aula como em "foi uma aula (.) que ousou pouco" na linha 409, ambos sem 
modalização). Destarte, ela é bem mais assertiva que Ana e é possível entender que, apesar de parecer se esforçar para manter o diálogo aberto, ela se vale de sua autoridade com professora da universidade, conduzindo o diálogo, corrigindo colega e ocasionalmente empregando uma linguagem que reduz o espaço dialógico como em "mas claro eu não sei, porque ela fazia o que estava previsto na folhinha" na linha 405. Ao falar 'claro', ela assinala para sua ouvinte que qualquer possiblidade de divergência seria considerada errada. Além disso, instâncias de engajamento por discordância na fala da professora da Prática de Ensino aparecem várias vezes, principalmente pelo uso do vocábulo 'mas' (no trecho 2, nas linhas 203 e 206, bem como no trecho 3, nas linhas 398, 405 e 419) sempre refutando os momentos em que a colega tenta amenizar os defeitos da aula, o que normalmente é acolhido pela sua interagente.

Entretanto, no momento de fechar a nota, quando Marta continua a mostrar maior poder na condução da negociação e avalia a aula como "sete e meio ou oito", podemos notar a insatisfação de Ana, que volta a argumentar em favor da estagiária, mas ela o faz com base em afeto (nas linhas 417 e 422, "fiquei lamentando") e apreciação positiva da aula ("uma aula tão rica, tão boa" em 423). Ela parece tentar aumentar a nota da aluna, dizendo como se sente em relação à aula e ao mesmo tempo “dando razões para essa emoção" que também contribuem para justificar porque o seu interagente deveria se sentir do mesmo modo (Micheli, 2010). Então, Marta propõe considerar a fala de Ana e aumentar a nota de forma que as duas concordem (em "você acha trinta eu acho uns vinte e cinco, fica vinte e oito", logo depois checando se a colega está de acordo com “entendeu?"), o que é muito bem recebido por Ana (“isso (.) perfeito") . Ana reforça mais ainda a ideia de que queria a consideração de sua opinião, argumentando que assim seria feita "justiça" ("pra gente...não ficar nem lá nem cá e ser injusto”). Essas últimas contribuições colaboram para a resolução dos problemas de intersubjetividade e elas finalmente chegam juntas à decisão de uma nota para o estágio de Lívia.

\section{CONSIDERAÇÕES FINAIS}

Este trabalho buscou investigar como se dá a negociação da avaliação do estágio após a apresentação de uma prova de aula examinando os elementos interpessoais no nível da semântica do discurso a partir do Sistema de Avaliatividade. Tal abordagem foi muito profícua para alcançar esse objetivo. Ao analisar as ocorrências de atitude, 
engajamento e gradação, foi possível entender um pouco melhor a interação na avaliação do estágio pelas professoras formadoras e chegar a algumas interpretações, que sintetizo a seguir.

Primeiramente, apreendemos que as professoras constroem sua argumentação de forma a defender posições divergentes: Ana, a professora regente, procura atenuar os problemas percebidos e expõe uma posição positiva sobre ela, enquanto Marta defende uma posição negativa sobre vários aspectos. Nos trechos selecionados, vemos discordâncias principalmente quanto aos materiais selecionados e o desenvolvimento das atividades pela estagiária. Percebemos que elas tentam manter a intersubjetividade e usam recursos de engajamento para a expansão dialógica, especialmente Ana. Sempre empregando graduação em sua fala para atenuar os problemas e acentuar o que foi bemsucedido, assim como a linguagem corporal para se fazer ouvir/entender (exibindo suas anotações, por exemplo), Ana se mostra determinada a participar efetivamente da avaliação da aluna. Mesmo assim, os dados sugerem que Marta tem autoridade sobre o processo decisório, posto que ela organiza os turnos, por vezes interrompe e corrige a colega e não deixa de impor sua opinião, apesar de algumas vezes parecer modalizada.

Portanto, por se orientarem por posições distintas, elas utilizam estratégias diversas para discordar. Ana muitas vezes pauta seus argumentos em observações subjetivas, usando a emoção como estratégia argumentativa (MICHELI, 2010), principalmente por afeto. Assim, ela parece tentar conquistar a empatia de sua interlocutora recordando o esforço da aluna na elaboração da aula, trazendo à baila exemplos de êxito e destacando a boa conduta da estagiária por julgamento positivo de capacidade, mas principalmente por afeto negativo tanto em relação a ela como avaliadora como quanto à aluna-avaliada. De qualquer forma, ela tende a primar pela concordância, ressaltando os pontos comuns e atenuando os divergentes ao trazer sua opinião de forma relativa, discreta.

Marta, por outro lado, mostra sua discordância mais abertamente, mas também com o cuidado de não entrar em conflito. A professora de Prática de Ensino usa muitas repetições para enfatizar seu ponto de vista, às vezes toma o turno por momentos mais longos sem considerar a voz da outra e também cita uma aula não assistida pela professora regente como estratégia de argumentação. Tal exemplo endossa a opinião de Marta, visto que a experiência é mostrada como um fato, algo que a outra não pode contestar. 
Assim, Marta parece assumir o controle de boa parte da interação, definindo que tópicos seriam postos sob o escrutínio das duas e dando a palavra final sobre eles. Mesmo consentindo em fazer uma média das marcações das duas fichas como nota final, todo o processo de avaliação teve grande influência dessa professora. Deste modo, muitos argumentos de Ana são refutados até ser convencida pela colega, mostrando que a premissa de que as duas tem o mesmo poder de decisão sobre a avaliação do estágio não é totalmente verdadeira. Há certa flexibilidade, mas o ponto de vista que vence parece ser o da Professora de Prática de Ensino.

Ao analisar a fala-em-interação entre os participantes da formação de professores, busco contribuir para um maior entendimento da prática social envolvida: a avaliação do estágio. Assim, essa pesquisa pode promover outros estudos sobre a negociação de significados entre os participantes desse ambiente educacional, tema que necessita ser mais explorado.

\section{REFERÊNCIAS}

CELANI, M. A. A. Ensino de Línguas Estrangeiras: ocupação ou profissão? In: LEFFA, V. J. (org) O professor de línguas estrangeiras: construindo a profissão. Pelotas: EDUCAT/ALAB, p. 21-40, 2001.

DENZIN, N..; LINCOLN, Y. O planejamento da pesquisa qualitativa: Teorias e abordagens. Porto Alegre: Artmed, 2006.

GARCEZ, P.; BULLA, G; LODER, L.. Práticas de pesquisa microetnográfica: geração, segmentação e transcrição de dados audiovisuais como procedimentos analíticos plenos. DELTA. Documentação de Estudos em Linguística Teórica e Aplicada (PUCSP. Impresso), 30, p. 257-288, 2014.

HALLIDAY, M. A. K., \& MATTHIESSEN, C. M. I. M. An introduction to functional grammar. London: Edward Arnold, 2004.

MARTIN, J. Beyond Exchange: APPRAISAL Systems in English. In: HUNSTON, S.; THOMPSON, G. (Ed.). Evaluation in Text: Authorial Stance and the Construction of Discourse. Oxford: Oxford University Press, p. 142-175, 2000.

MARTIN, J.R.; WHITE, P. R. R. The Language of Evaluation. New York: Palgrave Macmillan, 2005.

MICHELI, Raphael. Emotions as Objects of Argumentative Constructions. Argumentation, 24, p.1-17, 2010, 
MILLER, I.K. Formação de professores de línguas: da eficiência à reflexão crítica e ética. In: MOITA LOPES, L. P. (Org.). Linguística aplicada na modernidade recente: festschrift para Antonieta Celani. São Paulo: Parábola, p. 99- 121, 2013,.

PIMENTA, S. G.; LIMA, M. S. L. Estágio e docência. 2ª ed. São Paulo: Cortez, 2004.

SACKS, Harvey, SCHEGLOFF, Emmanuel A. e JEFFERSON, Gail. Sistemática elementar para a organização da tomada de turnos para a conversa. Veredas, 7, p. 9-73, 2003.

VIAN JR., O. O sistema de avaliatividade e os recursos para gradação em Língua Portuguesa: questões terminológicas e de instanciação. D.E.L.T.A, São Paulo, 25 (1), p. $99-129,2009$.

VIAN Jr. O. Avaliatividade, engajamento e valoração. D.E.L.T.A , 28 (1) São Paulo, p. 105-128, 2012,

VIAN Jr., O . Engajamento: monoglossia e heteroglossia. In:VIAN Jr.; O. SOUZA, A.; ALMEIDA, F. (org.). A linguagem da avaliação em língua portuguesa: estudos sistêmico-funcionais com base no Sistema da Avaliatividade. São Carlos, Pedro \& João Editores, p. 33-40, 2011.

WHITE, P. Valoração: a linguagem da avaliação e da perspectiva. Trad. Débora de Carvalho Figueiredo. Linguagem em (Dis)curso, Tubarão, 4 (esp), p. 177-205, 2004.

\section{A AUTORA}

Carla Cristina de Souza é doutoranda em Estudos da Linguagem da Pontifícia Universidade Católica do Rio de Janeiro. Fez a graduação em Letras (Português/Inglês, Bacharelado e Licenciatura) pela UFRJ e concluiu a Especialização em Linguística Aplicada e Mestrado em Linguística na UERJ. Trabalhou como Professora Substituta de Didática Especial de Inglês/Prática de Ensino de Português-Inglês na UFRJ. Hoje é professora de Inglês no Instituto Federal do Rio de Janeiro (IFRJ). Suas áreas de interesse compreendem Análise Crítica do Discurso, Linguística Aplicada, Linguística Sistêmico-Funcional, Multiletramentos, Gêneros Discursivos e Formação de Professores.

E-mail:wscarla@hotmail.com 


\section{Convenções de transcrição}

\begin{tabular}{|c|c|c|}
\hline . & (ponto final) & Entonação descendente \\
\hline$\ldots$ & (três pontos) & Pausa não medida \\
\hline$?$ & (ponto de interrogação) & Entonação ascendente \\
\hline , & (vírgula) & Entonação de continuidade \\
\hline$\uparrow$ & (seta para cima) & Mais agudo \\
\hline$\downarrow$ & (seta para baixo) & Mais grave \\
\hline palav- & (hífen) & Marca de corte abrupto \\
\hline pala::vra & (dois pontos) & Prolongamento do som (maior duração) \\
\hline pa la vra & (sublinhado) & Sílaba ou palavra enfatizada \\
\hline PALAVRA & (maiúsculas) & Intensidade maior ("volume" alto) \\
\hline${ }^{\circ}$ palavra ${ }^{\circ}$ & (sinais de graus) & Intensidade menor ("volume" baixo) \\
\hline$>$ palavra $<$ & $\begin{array}{l}\text { (sinais de maior do que e } \\
\text { menor do que) }\end{array}$ & Fala acelerada \\
\hline$<$ palavra> & $\begin{array}{l}\text { (sinais de menor do que e } \\
\text { maior do que) }\end{array}$ & Fala desacelerada \\
\hline hh & (série de h's) & Aspiração ou riso \\
\hline.$h$ & (h's precedidos de ponto) & Inspiração audível \\
\hline$=$ & (sinais de igual) & Elocuções contíguas, sem intervalo \\
\hline[] & (colchetes) & Início e fim de falas simultâneas/sobrepostas \\
\hline$(2,4)$ & (números entre parênteses) & $\begin{array}{c}\text { Medida de silêncio (em segundos e décimos } \\
\text { de segundos) }\end{array}$ \\
\hline$()$. & (ponto entre parênteses) & Micropausa de até 2/10 de segundo \\
\hline() & (parênteses vazios) & Fala que não pôde ser transcrita \\
\hline (palavra) & $\begin{array}{c}\text { (segmento de fala entre } \\
\text { parênteses) }\end{array}$ & Transcrição duvidosa \\
\hline $\begin{array}{l}\text { ((olha para } \\
\text { baixo)) }\end{array}$ & (parênteses duplos) & $\begin{array}{c}\text { Descrição de atividade não-vocal / } \\
\text { comentários do analista }\end{array}$ \\
\hline
\end{tabular}

Fonte: Adaptado de Sacks, Schegloff e Jefferson (1974); e Garcez, Bulla e Loder (2014) 